\title{
Otimização de método analítico para estudo da degradação do difenoconazol em substrato com adição de lodo ativado do esgoto doméstico tratado
}

A degradação de pesticidas em solos pode ser avaliada como uma possível solução para minimizar os efeitos da ação tóxica destes compostos recalcitrantes em alimentos cultivados e no meio em que ocorre este cultivo. Uma alternativa comum e sustentável é o uso de lodo ativado de esgoto doméstico tratado (LET) como coadjuvante em solos. $\mathrm{O}$ objetivo deste trabalho foi avaliar a influência do LET no perfil de degradação de um pesticida no solo. Partindo da hipótese de que o uso de LET em solos pode influenciar na degradação de pesticidas, foi implementada uma abordagem lab-to-field para determinação do decaimento do analito tóxico utilizando o difenoconazol (DFC), um fungicida da classe dos triazóis. Foram testadas duas técnicas para extração e clean-up das amostras e, para cada técnica foram testados dois solventes. Também otimizadas as condições cromatográficas por cromatografia gasosa acoplada a espectrometria de massas (CGEM) para identificação dos principais íons e quantificação do DFC. O experimento foi feito em quatro vasos contendo: somente solo; solo e LET na proporção $70 / 30 \%$, respectivamente; solo fortificado com DFC; e solo e LET na proporção $70 / 30 \%$, respectivamente, fortificado com DFC. Para o estudo da degradação foram retiradas alíquotas dos vasos durante 21 dias após dosagem de DFC na concentração de $20 \mathrm{mg} . \mathrm{Kg}-1$, respeitando frequência de coleta estabelecida. O método considerado mais eficiente para determinação de DFC utilizou extração com diclorometano sob ultrassom e clean up com a técnica de extração dispersiva em fase sólida, utilizando alumina como adsorvente. A partir dos resultados analíticos e da construção das curvas de degradação dos dois vasos que continham o analito, verificou-se que no primeiro dia após a dosagem houve uma queda brusca na concentração de DFC em ambos vasos, com mais intensidade no substrato só com solo. Nos dias seguintes o substrato com solo e LET apresentou maior decaimento do DFC em relação ao substrato com solo, confirmando variação significativa entre os substratos.

Palavras-chave: Biossólidos; Azol; CGEM.

\section{Analytical method optimization for study of difenoconazole degradation in substrate with addiction of treated activated domestic sewage sludge}

\begin{abstract}
Pesticide degradation in soils can be evaluated as a possible solution to minimize the effects of toxic action using recalcitrant compounds on cultivated food and the environment in which it occurs. A common and sustainable alternative is the use of treated sewage activated domestic sludge (TSS) as an adjuvant in soils. The objective of this work was to evaluate the influence of TSS on the degradation profile of a pesticide in the soil. Based on the hypothesis that the use of TSS in soils may influence pesticide degradation, a lab-to-field approach was implemented to TSS on the degradation profile of a pesticide in the soil. Based on the hypothesis that the use of TSS in soils may influence pesticide degradation, a lab-to-field approach was implemented to determine toxic analyte decay using diphenoconazole (DFC), a triazole class fungicide. Two techniques for sample extraction and clean-up were tested and for each technique two solvents
were tested. Also chromatographic conditions were optimized by gas chromatography coupled to mass spectrometry (GCMS) for identification of the main ions and quantification of DFC. The experiment was done in four vessels containing: soil only; soil and TSS in the proportion 70/30\%, respectively; soil fortified with DFC; and soil and TSS in the proportion $70 / 30 \%$, respectively, fortified with DFC. For the degradation study, aliquots were removed from the vessels for 21 days after DFC dosing at a concentration of $20 \mathrm{mg}$.Kg-1, respecting the established collection frequency. The method considered most efficient for the determination of DFC used dichloromethane under ultrasound extraction and clean up with the dispersive solid phase extraction technique, using alumina as adsorbent. From the analytical results and the construction of the degradation curves of the two vessels containing the analyte, it was observed that on the first day after dosing there was a sharp drop in the concentration of DFC in both vessels, with greater intensity in the soil only substrate. In the following days the substrate with soil and TSS presented higher decay of DFC in relation to the substrate with soil, confirming significant variation between substrates.
\end{abstract}

Keywords: Biosolids; Azole; GCMS.

Topic: Engenharia Ambiental

Reviewed anonymously in the process of blind peer.

Alex Mercio Mendez Larrosa (iD

Instituto Federal Sul-Rio-Grandense, Brasil

http://lattes.cnpq.br/0558481289592370

http://orcid.org/0000-0002-0141-9271

alexmerciolarrosa@yahoo.com.br

Giani Mariza Bärwald Böhm (it)

Instituto Federal Sul-Rio-Grandense, Brasil

http://lattes.cnpq.br/0429818788026737

http://orcid.org/0000-0002-2844-416X

bohmgiani@gmail.com

Pedro José Sanches Filho (iD

Universidade Federal do Rio Grande do Sul, Brasil

http://lattes.cnpq.br/9785390634457316

http://orcid.org/0000-0002-9852-8940

pjsans@ibest.com.br

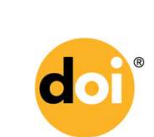

DOI: 10.6008/CBPC2179-6858.2020.001.0021
Received: 07/12/2019

Approved: 12/01/2020 lago Riveiro Santos Dutra (iD

Instituto Federal do Sul, Brasil

http://lattes.cnpq.br/9043224024765006

http://orcid.org/0000-0003-3290-463X

iagorivsd@gmail.com
Referencing this:

LARROSA, A. M. M.; BOHM, G. M. B.; SANCHES FILHO, P. J.; DUTRA, I. R. S.. Otimização de método analítico para estudo da degradação do difenoconazol em substrato com adição de lodo ativado do esgoto doméstico tratado. Revista Ibero Americana de Ciências Ambientais, v.11, n.1, p.222-235, 2020. DOI: http://doi.org/10.6008/CBPC2179$\underline{6858.2020 .001 .0021}$ 


\section{INTRODUÇÃO}

A qualidade do solo, da água e do ar se configuram como os três compartimentos que determinam a qualidade ambiental. Enquanto a água e o ar se definem comumente pelo grau de poluição que prejudica diretamente a saúde humana e os ecossistemas, a qualidade do solo não se limita apenas ao seu grau de poluição envolvendo no contexto o impacto na capacidade funcional deste compartimento ambiental (BUNNEMANN et al., 2018). Devido a quantidade ampla de microrganismos que executam as principais funções do ecossistema do solo, o caracterizando como um recurso limitado e amplamente não renovável, ele se torna um habitat único e complexo que contribui em processos com impactos em escala global (STORCK et al., 2018). Desde que o ser humano se apropriou de métodos agrícolas de cultivo dos alimentos no solo, este compartimento ambiental recebeu uma atenção especial, devendo suprir as necessidades para uma cultura produtiva qualitativamente e quantitativamente (JAISWAL et al., 2019; REY et al., 2019).

Neste contexto, os pesticidas são usados no solo para garantir a estabilidade da produção agrícola e mesmo não afetando diretamente a saúde humana, indiretamente bio-concentram em tecidos de organismos (CHANG et al., 2019) associando sua presença a alterações hormonais (alterações no sistema endócrino), falhas no desenvolvimento do sistema nervoso e formação de tumores (em alguns casos malignos) (FISHER et al., 2018; SHI et al., 2017; MEIS et al., 2016). A contaminação pelo uso de pesticidas no solo merece atenção da comunidade científica não apenas pelo risco envolvido no consumo de alimentos cultivados e também pela ótica do desequilíbrio ecológico promovido pela degradação dos recursos naturais adjacentes ao solo onde o pesticida foi aplicado como a água (através de lençóis freáticos), a flora e fauna (HENDRIKS et al., 2019). Uma prática comum que visa minimizar o impacto de pesticidas no solo é a adição de resíduos industriais e domiciliares tratados como biorremediadores atuantes sobre o efeito tóxico causado pela adição de poluentes orgânicos persistentes (POPs) (EVANS et al., 2011).

Entre os pesticidas mais comuns no cenário agrícola os fungicidas se destacam com grande abrangência no mercado. E dentre muitas classes de fungicidas os azóis representam um grupo de substâncias amplamente utilizadas tanto na agricultura como na indústria farmacêutica (SHAHINASI et al., 2017). Este grupo apresenta, principalmente, duas subclasses com base no número de átomos de nitrogênio em um anel. A primeira classe inclui imidazóis, com dois átomos de nitrogênio em um anel azol, enquanto outra classe inclui triazóis, que contém três átomos de nitrogênio em um anel cíclico (PRASAD et al., 2016). Um dos triazóis mais comuns no mercado como fungicida agrícola é o difenoconazol (DFC), que se caracteriza como fungicida por interferir na biossíntese do ergosterol e inibir a desmetilação de esteroides comprometendo o crescimento dos fungos (KANG et al., 2017; SZPYRKA et al., 2016). Aplicado em diversas culturas, o DFC (cis, trans-3-cloro-4-[4-metil-2- (1H-1,2,4-triazol-1-ilmetil) -1,3-dioxolan-2-il] fenil-4-clorofenil éter]) é um pesticida de uso agrícola e domissanitário de aplicação foliar e da aplicação em sementes, sendo que seu limite máximo de resíduos (LMR) é de $0,5 \mathrm{mg} \mathrm{kg}^{-1} \mathrm{em}$ algumas culturas e sua ingestão diária aceitável (IDA) é de $0,6 \mathrm{mg} \mathrm{kg}^{-1}$ p.c. (ANVISA, 2015). Estudos avaliaram a cinética de dissipação do DFC em solos com o objetivo de avaliar o impacto do fungicida neste recurso natural, como as pesquisas de Banerjee et al. (2008) 
e Zhang et al. (2015a) que estudaram o padrão de dissipação do fungicida em culturas e produtos em diferentes doses para determinar seus intervalos pré-colheita (PHIs), revelando a importância de soluções qualificadas para minimizar o efeito deste agrotóxico no meio ambiente.

O DFC, assim como todos triazóis e a maioria dos pesticidas, apresenta quiralidade e suas quatro formas conhecidas (Figura 1) se comportam de formas diversas no solo apresentando toxicidade enantiosseletiva. Levando em consideração que os processos de absorção, distribuição e degradação no organismo e ambiente em que estes se encontram são frequentemente enantiosseletivos, revelando um imenso campo de pesquisa onde avaliações de risco dos resíduos das pesticidas quirais em alimentos e matriz ambiental com base nos dados obtidos pelos métodos aquirais são incompletos e inespecíficos (ZHANG et al., 2015b; Ll et al., 2012).

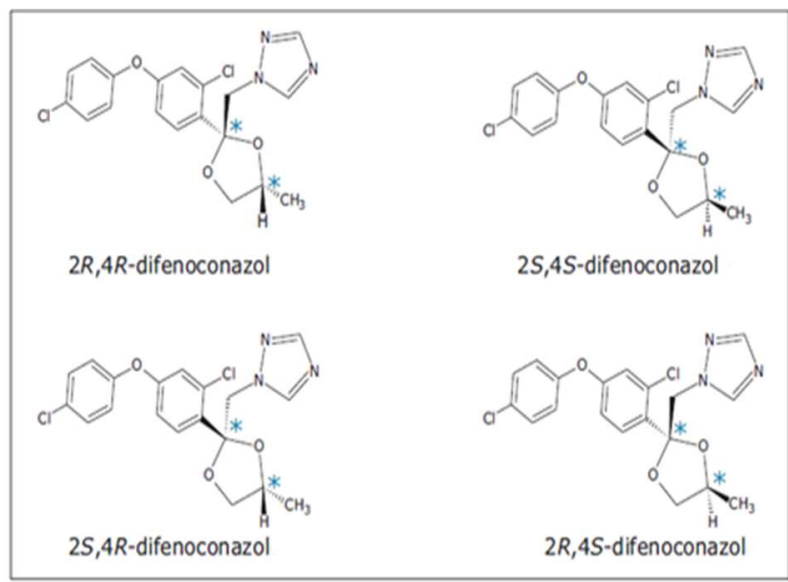

Figura 1: Estrutura dos quatro estereoisômeros do DFC. Os asteriscos indicam os centros estereogênicos.

Fonte: Twohig et al. (2013).

Com o objetivo de minimizar o efeito de pesticidas no solo vários coadjuvantes biológicos já foram inseridos no solo como bactérias (ARYA et al., 2015; MÓNICA et al., 2016), fungos (SPINA et al., 2018; GUPTA et al., 2017; MAQBOOL et al., 2016), biochar (ZHEN et al., 2018 e CHENG et al., 2017), e inclusive o tema revela estudos no campo da edição genética envolvendo biologia computacional e abordagens multi-óticas com intuito de desenvolver um micróbio, com gene funcional de interesse, para degradação de um recalcitrante específico (JAISWAL et al., 2019). No atual panorama demográfico o lodo ativado de esgoto doméstico tratado (LET) se torna uma alternativa viável como biodegradante, devido seu uso atualmente comum atrelado à demanda global por energias renováveis, através do uso do LET como biomassa, e substratos para fertilização de solos (KACPRZAK et al., 2017). Ainda se trata com preconceito da sociedade o uso de LET como fertilizante ou biodegradante no solo devido à sua origem, entretanto em muitos países desenvolvidos seu uso como fertilizante é comum e gera muita produção científica no estudo dos seus benefícios como adjuvante no solo (EVANS et al., 2011).

Estudos recentes investigam os efeitos quantitativos e qualitativos do DFC que prejudicam características estruturais e funcionais da microbiota em solos devido ao seu uso prolongado e, muitas vezes, sofrem a falta de fiscalização dos órgãos competentes no seu uso correto (FILIMON et al., 2018), tanto que o DFC foi identificado no LET em certas regiões como em Madri, na Espanha, onde foi detectado DFC no LET 
que é usado como fertilizante orgânico em culturas da região, de acordo com García-Valcárcel et al. (2011), que confirmaram a presença de compostos azólicos nesta matéria prima, em quantidades que podem produzir efeitos adversos no meio ambiente. Outra característica dos azóis que merece muita atenção atualmente diz respeito a saúde pública. A crescente frequência de infecções fúngicas que acarretam risco de vida provoca o aumento do uso profilático de azóis em pacientes do alto risco se tornou um fator importante para o surgimento e a disseminação da resistência aos medicamentos azólicos (GARCIA-RUBIO et al., 2017; AZEVEDO et al., 2015). Neste contexto, é determinante que se avalie que a degradação do DFC depende de vários fatores que incluem desde os aspectos regionais, características físico-químicas do solo, atividade microbiana do solo e dosagens de DFC aplicadas. O objetivo deste trabalho foi investigar a degradação do DFC no solo com adição de LET em uma abordagem lab to farm, através de metodologia analítica otimizada para determinação do analito nas amostras.

\section{MATERIAIS E MÉTODOS}

\section{Reagentes, solventes e materiais}

Para o desenvolvimento do trabalho foi utilizado o produto comercial Score 250 EC (Syngenta), concentrado para emulsão com $250 \mathrm{~g} \mathrm{~L}^{-1}$ do princípio ativo DFC. A partir do produto comercial foi feita uma solução estoque de $20 \mathrm{mg} \mathrm{L}^{-1} \mathrm{em}$ DCM. Os solventes acetonitrila (ACN), acetona e diclorometano (DCM) de grau analítico (Synth). Cloreto de sódio (Merck), sulfato de sódio anidro (Merck) ativado em estufa a $100^{\circ} \mathrm{C}$ por 6 horas e armazenado em dessecador. Óxido de alumínio neutro (alumina) 0,05-0,2 mm/70-270 mesh ASTM (Macherley-Nagel) ativado em mufla a $400^{\circ} \mathrm{C}$ durante 8 horas e armazenado em dessecador. Para determinação dos índices de retenção foi utilizada solução padrão de n-alcanos, resultantes da mistura dos padrões C8 a C20 e C21 e C40 (Sigma-Aldrich). O solo utilizado foi o argissolo vermelho-amarelo distrófico (PVAd) fornecido pela Embrapa e o LET proveniente da estação de tratamento de esgoto (ETE) da Companhia Rio-grandense de Saneamento (CORSAN) da cidade de Rio Grande (RS) que segue o processo para tratamento de esgotos de lodos ativados em tanques de aeração.

\section{Caracterização físico-química do solo e LET}

Foram avaliadas umidade por gravimetria, matéria orgânica por perda de voláteis em forno de mufla $\left(550^{\circ} \mathrm{C}\right), \mathrm{pH}$ por potenciometria (relação amostra: água 1:5) e carbono orgânico em g kg${ }^{-1}$ por combustão úmida. Todas análises seguiram as metodologias utilizadas por Tedesco et al. (1995).

\section{Otimização do método cromatográfico}

Para otimização das condições cromatográficas foi utilizada uma solução de $500 \mathrm{mg} \mathrm{L}^{-1}$ de DFC em DCM. As análises para identificação do DFC foram feitas em CGEM em um equipamento Shimadzu QP 2010 com coluna de polidimetilsiloxano (PDMS) com 5\% de grupos fenila (Restek5MS), com hélio como gás de arraste. Partindo-se das condições estabelecidas para fungicidas por Hladik et al. (2012), conforme Tabela 1, 
foram otimizados: os modos de injeção (split e splitless), modo de análise do espectrômetro de massas (scan e SIM) e a programação da temperatura do forno (Tabela 1). As condições iniciais do CGEM foram: $1 \mu$ L do extrato foi injetado em modo splitless (temperatura de injetor $275^{\circ} \mathrm{C}$ ). Com energia de ionização do CGEM de $70 \mathrm{eV}$.

Tabela 1: Programação de forno no CGEM conforme as condições estabelecidas por Hladik et al. (2012).

\begin{tabular}{|l|l|l|}
\hline Rampa $\left({ }^{\circ} \mathrm{C} \mathrm{min}^{-1}\right)$ & Temperatura & Tempo de permanência (min) \\
\hline 0 & 80 & 0,5 \\
\hline 10 & 180 & 0 \\
\hline 5 & 220 & 1 \\
\hline 4 & 280 & 1 \\
\hline 10 & 300 & 0 \\
\hline
\end{tabular}

Para avaliar a influência da matriz na análise cromatográfica foi preparada uma amostra com $100 \mathrm{~g}$ de uma mistura de solo e LET na proporção $70 / 30 \%$ com fortificação de $20 \mathrm{mg} \mathrm{kg}^{-1}$ do DFC. O método de extração foi o método utilizado por Gonçalves et al. (2004), que não aplica clean up ao extrato obtido. A determinação da linearidade do método cromatográfico otimizado foi realizada através da construção de uma curva de calibração com soluções de trabalho na faixa de 25 a $200 \mathrm{mg} \mathrm{L}^{-1} \mathrm{com}$ DCM, todas as soluções foram armazenadas sob refrigeração e protegidas contra a luz com folha de alumínio. 0 padrão de $50 \mathrm{mg} \mathrm{L}^{-1}$ foi analisado cinco vezes para o estudo de precisão que foi expresso através do desvio relativo em porcentagem (RSD\%). A exatidão foi estudada através da aplicação da curva para cálculo da concentração da solução de $50 \mathrm{mg} \mathrm{L}^{-1}$ a partir de sua área, sendo a diferença entre o valor da solução e o valor encontrado a partir da curva, expresso como erro relativo. O limite de deteç̧ão (LD) e o limite de quantificação (LQ) foram calculados com base da análise de brancos, considerando três vezes o valor de RSD do branco e dez vezes o valor do RSD do branco (ambos divididos pelo coeficiente angular da curva), para LD e LQ, respectivamente (LANÇAS, 2004).

Os compostos foram identificados por comparação dos tempos de retenção com a solução de trabalho e pela biblioteca NIST instalada no programa GCMSolutions versão 2.5 (Shimatzu) do CGEM, considerando similaridades superiores a $80 \%$. Para confirmação da identidade dos compostos na amostra foi calculado (conforme Equação 1) o índice de retenção (IR), utilizando padrão de $n$-alcanos conforme equação de Van den Dool et al. (1963).

$$
I R=100 n+100\left(\frac{t_{R(C)}-t_{R(n)}}{t_{R(n+1)}-t_{R(n)}}\right)
$$

Equação 1:

Onde $t_{R(n)}$ e $t_{R(n+1)}$ são tempos de retenção dos $n$-alcanos de referência eluídos antes e imediatamente depois do composto químico ' $C$ '; $t_{R(c)}$ é o tempo de retenção do composto ' $C$ ' (VON MÜHLEN, 2009).

\section{Extração e clean up}

Para otimizar o método de pré-tratamento para detectar o DFC nas amostras, diferentes solventes de extração foram investigados para melhorar a eficiência de extração. Para determinar o método mais eficiente foram preparados dois vasos contendo $100 \mathrm{~g}$ da mistura de solo e LET na proporção 70/30\% em base seca (BS), sendo uma fortificada com DFC a $20 \mathrm{mg} \mathrm{kg}^{-1}$ e a outra não. Após homogeneização dos 
substratos foram retiradas amostras para extração e clean up em triplicata. 0 experimento sem dosagem recebeu o mesmo tratamento para confirmação de ausência dos compostos encontrados no produto comercial no solo com LET. Os métodos de extração usaram o fundamento da extração por solventes sob US, que é indicada para extrair componentes orgânicos voláteis e semi-voláteis de sólidos como solos, lodos e resíduos (EPA 3550C, 2000). Os métodos testados basearam-se no método adotado por Gonçalves et al. (2004), utilizando os solventes extratores DCM e ACN (codificando os métodos como GDCM e GACN, respectivamente), e no método adotado por Kang et al. (2017), avaliando os solventes extratores DCM e ACN (codificando os métodos como KDCM e KACN, respectivamente). Para o clean-up dos extratos obtidos através dos métodos GDCM e GACN foi usada a técnica de cromatografia líquida preparativa (CLP), com alumina como fase estacionária (SHALABI et al., 2017), e para o clean-up dos extratos obtidos dos métodos KDCM e KACN foi usada a técnica da extração em fase sólida, utilizando alumina como adsorvente, método utilizado pelo próprio Kang et al. (2017).

\section{Extração}

O método I seguiu a metodologia adotada por Gonçalves et al. (2004) que consistiu na extração de 5 $\mathrm{g}$ de amostra com $5 \mathrm{ml}$ de solvente em erlenmeyer e colocados em banho de US modelo USC1400A (UNIQUE) durante 15 min - por três ciclos - após cada ciclo o extrato foi transferido para um mesmo béquer, através de um funil com filtro de papel qualitativo (previamente lavado com o solvente utilizado), contendo uma porção de sulfato de sódio anidro. O béquer com $15 \mathrm{ml}$ do extrato foi evaporado em capela para posterior clean up. $\mathrm{O}$ método II seguiu a metodologia adotada por Kang et al. (2017) que consiste na extração de $10 \mathrm{~g}$ da amostra em tubo de centrífuga com $10 \mathrm{ml}$ do solvente em banho de US por $15 \mathrm{~min}$. Após a extração foi adicionado $3 \mathrm{~g}$ de sulfato de sódio anidro e $2 \mathrm{~g}$ de cloreto de sódio a mistura e agitada em vórtex por $3 \mathrm{~min}$, para posterior centrifugação por $5 \mathrm{~min}, 3 \mathrm{ml}$ do sobrenadante foram coletados, evaporados e submetidos posteriormente para clean up.

\section{Clean up}

Para o clean up do extrato obtido no método I houve otimização de procedimento utilizando mini coluna de cromatografia líquida preparativa (CLP) conforme Shalabi et al. (2017), com óxido de alumínio (alumina) como fase estacionária e acetona como fase móvel. O extrato obtido na extração por US foi diluído em $1 \mathrm{ml}$ de acetona, homogeneizado com 0,5 mg de alumina, evaporado, adicionado na CLP (recheada com uma porção de sulfato de sódio anidro no início da coluna, a fase estacionária e outra porção de sulfato de sódio anidro no final da coluna). Foram coletadas três frações de $5 \mathrm{ml}$ para determinar o volume de eluição do DFC. Cada fração foi evaporada, reconstituída em $1 \mathrm{ml}$ de DCM e analisado em CGEM.

Para o clean-up do extrato obtido no método II foi usada a técnica da extração dispersiva em fase sólida utilizando alumina como adsorvente. 0 extrato obtido foi diluído em $1 \mathrm{ml}$ do solvente utilizado na extração, homogeneizado com 0,05 g de alumina, agitado em vórtex por $30 \mathrm{seg}$. e centrifugado por 5 min. 
Após centrifugação o sobrenadante foi coletado, filtrado, avolumado em $1 \mathrm{ml}$ e analisado em CGEM. Os dois métodos utilizados são ilustrados na Figura 2.

Para avaliação dos métodos de extração e clean up foram utilizadas recuperações considerando as diferenças entre as concentrações obtidas através de cada metodologia em relação ao valor teórico esperado (utilizando as curvas de calibração em função do tratamento de cada método), e a precisão foi avaliada através do RSD em relação as triplicatas.

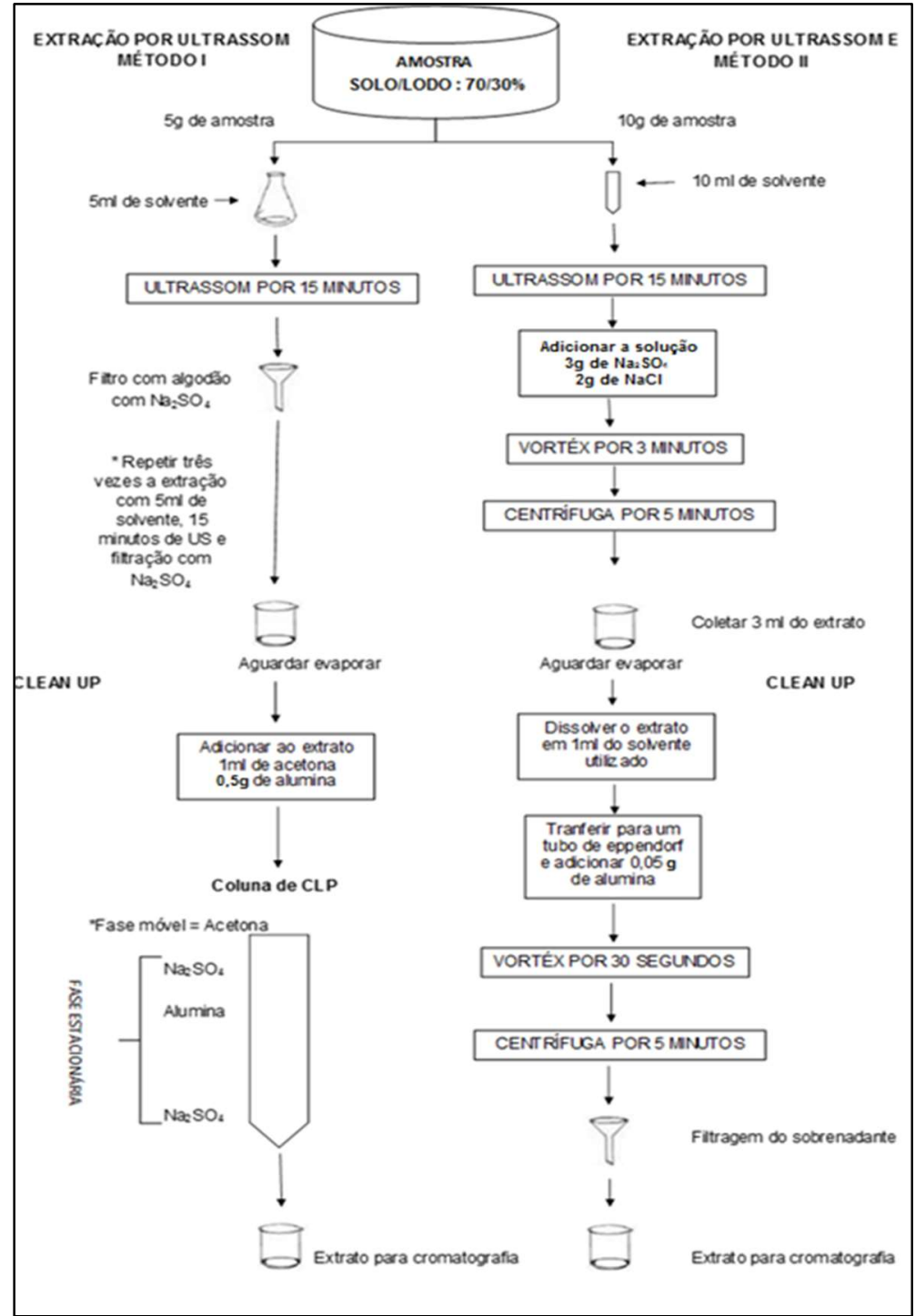

Figura 2: Métodos de extração e clean up modificados.

Fonte: Kang et al. (2017), Gonçalves et al. (2004) e Shalabi et al. (2017).

\section{Experimento de degradação}

O experimento de degradação foi realizado em bancada com preparação de quatro vasos para acompanhamento do perfil de degradação (Tabela 2). Um vaso contendo $500 \mathrm{~g}$ (BS) de solo, um vaso contendo 500 g (BS) da mistura de solo com LET na proporção de 70/30\%, respectivamente, um vaso contendo $500 \mathrm{~g}(\mathrm{BS})$ da mistura de solo com LET na proporção de 70/30\%, respectivamente, com adição de $20 \mathrm{mg} \mathrm{kg}^{-1}$ de pesticida e um vaso contendo $500 \mathrm{~g}$ do solo em BS com adição de $20 \mathrm{mg} \mathrm{kg}^{-1}$. 
Otimização de método analítico para estudo da degradação do difenoconazol em substrato com adição de lodo ativado do esgoto doméstico tratado

Tabela 2: Experimentos de bancada.

\begin{tabular}{|l|c|}
\hline Substratos & Código \\
\hline Vaso com $500 \mathrm{~g}(\mathrm{BS})$ de solo. & VSB \\
\hline Vaso contendo $500 \mathrm{~g}(\mathrm{BS})$ da mistura de solo com LET na proporção de 70/30\%, respectivamente. & VSLB \\
\hline $\begin{array}{l}\text { Vaso contendo } 500 \mathrm{~g}(\mathrm{BS}) \text { da mistura de solo com LET na proporção de 70/30\%, respectivamente, com adição de } 20 \mathrm{mg} \\
\mathrm{kg}^{-1} \text { de pesticida. }\end{array}$ & VSLD \\
\hline Vaso contendo $500 \mathrm{~g}$ de solo em BS com adição de $20 \mathrm{mg} \mathrm{kg}^{-1}$. & VSD \\
\hline
\end{tabular}

Para determinar o perfil de degradação do pesticida no solo com adição de LET foi seguido o método experimental utilizado por Kang et al. (2017) que consiste na coleta de amostras aleatórias a partir de $2 \mathrm{~h}$ (considerada como a concentração inicial), 1,2,3,5,7,10, 14 e 21 dias após a aplicação de pesticida. Todos vasos foram cuidadosamente homogeneizados anteriormente a cada coleta e as amostras foram retiradas (em triplicata) para extração, clean up e análise em CGEM.

Com o método otimizado foram determinadas as concentrações residuais de DFC nos extratos obtidos das amostras coletadas de VSLD e VSD nos dias indicados do experimento. A partir destes dados foi construída a curva de degradação relacionando a porcentagem de DFC remanescente, considerando no tempo zero a concentração inicial de $20 \mathrm{mg} \cdot \mathrm{kg}^{-1}$ correspondendo a $100 \%$, por tempo em dias. Para determinar se houve homogeneidade entre as variâncias dos perfis de degradação do VSLD e VSD foi feito análise de variância, através do software Statistica 7.1 (STATSOFT EUA).

\section{RESULTADOS E DISCUSSÃO}

\section{Caracterização do solo e do LET}

A Tabela 3 apresenta a caracterização do solo e do LET, evidenciando que o LET apresenta um alto teor de matéria orgânica (MO) e umidade, enquanto o solo apresenta baixa umidade e baixo teor de matéria orgânica, que pode indicar que o solo utilizado (PVAd) tem fertilidade química predominantemente baixa. Os resultados de umidade foram $66 \%$ para LET e 11\% para solo. Em relação ao LET esse resultado foi inferior aos obtidos por Ingelmo et al. (2012), que obteve 94,5\% para o LET.

Tabela 3: Resultados da caracterização do LET e do solo.

\begin{tabular}{|l|l|l|l|l|}
\hline & Umidade \% & MO \% & $\mathrm{pH}$ & $\mathrm{C} \mathrm{mg} \mathrm{kg}^{-1}$ \\
\hline LET & 66,0 & 60 & 6,6 & 307,0 \\
\hline SOLO & 11,0 & 4,3 & 4,5 & 25,3 \\
\hline
\end{tabular}

O teor de 60\% de MO do LET confere a este LET uma característica desejável para sua aplicação como fonte de nutrientes para o solo agrário (BOHM et al., 2016). O pH do LET 6,6 conforme Tedesco (1995) está dentro da faixa desejada que é $5,5-7,0$. Os teores de carbono obtidos para LET e solo foram $307,0 \mathrm{mg} \mathrm{kg}^{-1} \mathrm{e}$ $25,3 \mathrm{mg} \mathrm{kg}^{-1}$, respectivamente. O elevado teor de carbono no LET pode proporcionar elevada atividade microbiana através da respiração quando adicionado a solos (MOREIRA et al., 2004).

\section{Otimização do método cromatográfico}

A Figura 3 apresenta os cromatogramas obtidos com injeção splitless (a) e split (b) em modo scan para a solução de $500 \mathrm{mg} \mathrm{L}^{-1}$ do produto comercial Score $250 \mathrm{EC}$ nas condições conforme Hladik et al. (2012). 
Foi observado que os cromatogramas revelaram que o produto comercial apresenta o DFC com duas formas quirais com tempo de retenção de 64,923 e 65,111 min (identificados na tabela 2 e indicados na Figura 3 a1 e b2). A presença dos dois isômeros do DFC já foi observados em estudos de Szpyrka et al. (2016). Também foi possível identificar a presença outros compostos em grande quantidade, na sua maioria hidrocarbonetos (indicados e identificados na Figura 3 b2 e na tabela 4, respectivamente) na faixa entre 7,907 e 8,080 min.

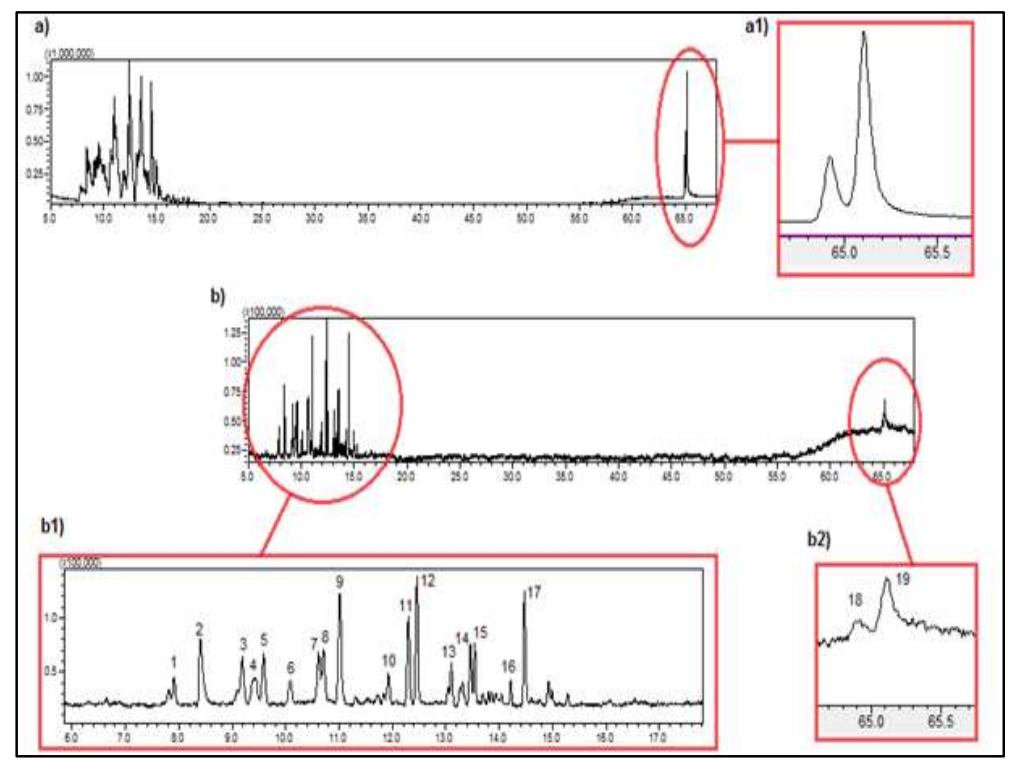

Figura 3: Cromatogramas obtidos dos compostos encontrados no produto comercial: a) Injeção splitless a1) DFC em modo splitless b) Injeção Split b1) e b2).

Tabela 4: Compostos encontrados no produto comercial.

\begin{tabular}{|l|l|l|l|l|}
\hline Pico & Composto químico & Tempo de retenção (min) & Área do pico (\%) & Massa molecular \\
\hline 1 & 1-Hexanol, 2-etil- & 7,91 & 2.37 & 130,2 \\
\hline 2 & 2-Pirrolidinona, 1-metil- & 8,40 & 10.80 & 99 \\
\hline 3 & Benzeno, 1-metil-3-propil- & 9,19 & 5.55 & 134 \\
\hline 4 & Benzeno, 1-metil-4-propil- & 9,41 & 4.02 & 134 \\
\hline 5 & Benzeno, 1-etil-3,5-dimetil-* & 9,58 & 4.98 & 134 \\
\hline 6 & Benzeno, 1-metil-2-propil* & 10,08 & 2.18 & 134 \\
\hline 7 & Benzeno, etil-dimetil (isomero)* & 10,62 & 4.84 & 134 \\
& Benzeno, etil-dimetil (isomero)* & & & \\
\hline 8 & & 10,71 & 5.06 & 134 \\
\hline 9 & Benzene, etil-dimetil (isomero)* & 11,01 & 12.77 & 134 \\
\hline 10 & Benzeno, etil-dimetil (isomero)* & 11,92 & 1.99 & 134 \\
\hline 11 & Benzeno, tetrametil (isomero)* & 12,30 & 6.93 & 134 \\
\hline 12 & Benzeno, tetrametil (isomero)* & 12,46 & 10.28 & 134 \\
\hline 13 & Benzeno, 1-metil-2-(2-propenil)* & 13,11 & 2.78 & 132 \\
\hline 14 & 1H-Indeno, 2,3-dihidro-5-metil-* & 13,46 & 4.67 & 132 \\
\hline 15 & Benzeno, 2-etil-1,4-dimetil-* & 13,54 & 4.18 & 134 \\
\hline 16 & Benzeno, 1-metil-4-(1-metilpropil)-* & 14,22 & 1.49 & 148 \\
\hline 17 & Naftaleno & 14,48 & 8.97 & 128 \\
\hline 18 & DFC & 64,92 & 1.51 & 405 \\
\hline 19 & DFC & 65,11 & 4.63 & 405 \\
\hline
\end{tabular}

*Não obtiveram confirmação do IR, por padrão de n-alcanos por Van den Dool e Kratz.

Embora o modo splitless tenha apresentado áreas maiores, o que implicaria em maior sensibilidade e menores LD e LQ para o DFC, o modo split foi mais adequado para caracterização do produto comercial em função da elevada concentração dos hidrocarbonetos aromáticos que ficaram melhor resolvidos neste modo na razão 1:20. A partir do estudo dos espectros de massa do DFC, apresentados na Figura 4, em modo scan 
foi possível identificar os principais íons resultantes das quebras deste analito, desta forma foram selecionados os íons de maior intensidade, m/z 265 e 323, para posteriores análises em GCMS em modo SIM.

Buscando um menor tempo de análise para identificar todos compostos o forno foi reprogramado conforme Tabela 5. Com esta programação o DFC com suas duas formas quirais foram identificadas nos tempos de 54,85 e 55.04 min. Porém quando analisamos os extratos referentes a amostra fortificada (para avaliar a interferência da matriz), foi observado que alguns compostos poderiam ser detectados após o tempo proposto pela corrida cromatográfica. Em função disto o tempo final foi prolongado por mais 20 min.

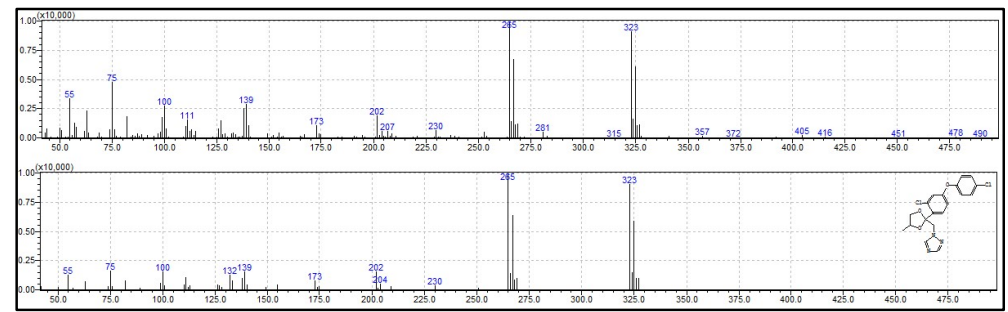

Figura 4: Comparação dos espectros de massa para o DFC com o espectro da biblioteca NIST.

Tabela 5: Reprogramação do forno.

\begin{tabular}{|l|l|l|}
\hline Rampa $\left({ }^{\circ} \mathrm{C} \mathrm{min}^{-1}\right)$ & Temperatura final $\left({ }^{\circ} \mathrm{C}\right)$ & Tempo de permanência $(\min )$ \\
\hline 0 & 80 & 0 \\
\hline 10 & 120 & 0 \\
\hline 3 & 220 & 5 \\
\hline 10 & 290 & 20 \\
\hline
\end{tabular}

Visando o aumento da sensibilidade aliada com clean up eletrônico as análises cromatográficas dos extratos foram conduzidas com injeções splitless de $1 \mu \mathrm{L}$ em modo SIM utilizando os íons m/z 265 e 323 . Este método se comportou de forma linear, considerando como sinal analítico a soma das áreas dos dois isômeros em relação a concentração, com um coeficiente de correlação linear $\left(R^{2}\right)$ de 0,999 . O método foi considerado preciso com RSD de 4,2\% e exato com erro relativo de 2,5\%. O LD e LQ foram de 0,01 $\mathrm{mg} \mathrm{L}^{-1}$ e 0,03 $\mathrm{mg} \mathrm{L}^{-1}$, respectivamente, revelando valores aceitáveis em conformidade com Zhao et al. (2019).

\section{Extração e clean up}

Observando os dados da Tabela 6 o método KDCM apresentou a melhor recuperação $(79,8 \pm 3,1 \%)$, com precisão aceitável segundo Zhao et al. (2019). Considerando as recuperações de $100 \%$ e os LD e LQ do método cromatográfico, os LDs e LQs em relação a amostra, seguindo esta metodologia, estariam na faixa de 0,001 e 0,003 $\mathrm{mg} \mathrm{kg}^{-1}$ (ZHAO et al., 2019). E além disto, o tempo envolvido nos métodos GDCM e GACN é maior que nos métodos KDCM e KACN.

Tabela 6: Recuperação, RSD e tempo médio dos métodos analisados.

\begin{tabular}{|l|l|l|l|}
\hline Método de Extração & Recuperação (\%) & RSD(\%) & Tempo médio(min) \\
\hline GDCM & 40,7 & 2,7 & 60 \\
\hline GACN & 24,6 & 3,3 & 60 \\
\hline KDCM & 79,8 & 3,1 & 30 \\
\hline KACN & 40,5 & 0,0 & 30 \\
\hline
\end{tabular}

Os métodos de extração GDCM e GACN (com volume de eluição na CLP definido nos primeiros $5 \mathrm{ml}$ 
de acetona), apresentaram menores recuperações de DFC. Também podemos observar na figura 5a que o processo de clean up não se apresentou efetivo nestes métodos, inclusive na determinação do DFC (Figura $5 b)$, resultando em muitos compostos no extrato que poderiam danificar ou sobrecarregar a coluna cromatográfica e, além disto, as quantidades de solvente envolvidas nestes métodos os tornam menos econômicos e mais agressivos ao meio ambiente e aos analistas. A Figura 5c compara os cromatogramas dos extratos obtidos por KDCM e KACN em modo SIM, onde se percebe a eliminação dos compostos interferentes através do clean up eletrônico proporcionado por esse modo, além de confirmar a melhor recuperação descrita pela Tabela 6 .

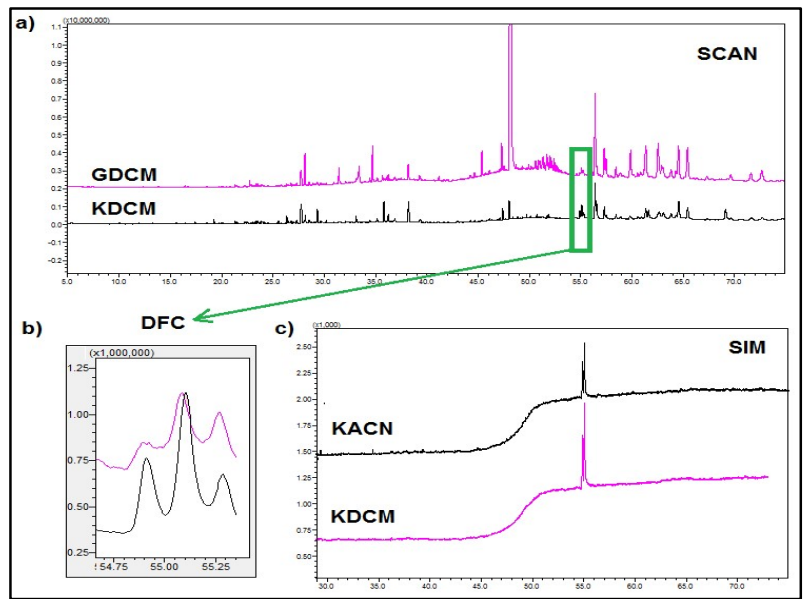

Figura 5: Cromatogramas em modo SIM e scan. a) Comparação entre métodos GDCM e KDCM em modo scan. b) DFC em evidência nos métodos em modo scan. c) Comparação entre os cromatogramas dos extratos obtidos por KDCM e KACN em modo SIM.

\section{Experimento de degradação}

A tabela 7 e a Figura 6 apresentam os resultados de DFC residual nas amostras retiradas nos dias propostos do estudo de degradação. Podemos observar que em ambos os tratamentos houve uma grande queda, de 79,5\% para o VSLD e 89,9\% para o VSD revelando que o substrato VSD apresentou maior redução nas primeiras 24 horas. Este comportamento sugere que a maior porcentagem de $\mathrm{MO}$ e umidade reduzem a dissipação do pesticida. A MO favorece uma interação mais forte com compostos de baixa polaridade com o solo em função de sua polaridade, por outro lado o alto teor de umidade do LET está relacionado com uma baixa granulometria do LET, o que pode justificar uma menor aeração que pode dificultar a dissipação do DFC para atmosfera (SANCHES FILHO et al., 2018). No segundo dia e no terceiro dia este comportamento se inverte, revelando valor maior da concentração de pesticida no vaso contendo substrato com solo, que pode evidenciar que a presença do LET favoreceu a degradação. A partir do sexto dia o DFC residual se estabilizou nos dois substratos até o vigésimo primeiro dia.

Tabela 7: Quantidade Residual de DFC no substrato com solo e LET fortificado com pesticida (VSLD) e substrato com solo fortificado com pesticida (VSD).

\begin{tabular}{|l|l|l|}
\hline Dias & Residual DFC VSLD $\left(\mathrm{mg} \mathrm{Kg}^{-1}\right)$ & Residual DFC VSD $\left(\mathrm{mg} \mathrm{Kg}^{-1}\right)$ \\
\hline 0 & $23,7 \pm 1,0 \%^{\mathrm{ax}}$ & $23,4 \pm 0,4 \%^{\mathrm{a} x}$ \\
\hline 1 & $4,9 \pm 6,4 \%^{\mathrm{by}}$ & $2,7 \pm 19,4 \%^{\mathrm{bx}}$ \\
\hline 2 & $1,0 \pm 6,1 \%^{\mathrm{cx}}$ & $1,5 \pm 18,5 \%^{\mathrm{cd} y}$ \\
\hline 3 & $0,8 \pm 10,1 \%^{\mathrm{cx}}$ & $1,7 \pm 9,1 \%^{\mathrm{bcy}}$ \\
\hline
\end{tabular}




\begin{tabular}{|l|l|l|}
\hline 6 & $0,8 \pm 5,7 \%$ cd $x$ & $0,6 \pm 17,8 \%$ de $x$ \\
\hline 8 & $0,8 \pm 12,3 \%$ cd $x$ & $0,6 \pm 20,5 \%$ de $x$ \\
\hline 10 & $0,4 \pm 7,3 \% d x$ & $0,7 \pm 10,0 \%$ de $x$ \\
\hline 14 & $0,4 \pm 7,9 \% d x$ & $0,5 \pm 8,1 \%$ de $x$ \\
\hline 21 & $0,3 \pm 5,5 \% d x$ & $0,3 \pm 20,0 \%$ ex \\
\hline
\end{tabular}

Médias com letras idênticas na coluna $(a, b, c, d, e)$ ou na linha $(x, y)$ não diferiram entre si pelo método de Tuckey ( $p$ $\leq 0,5)$.

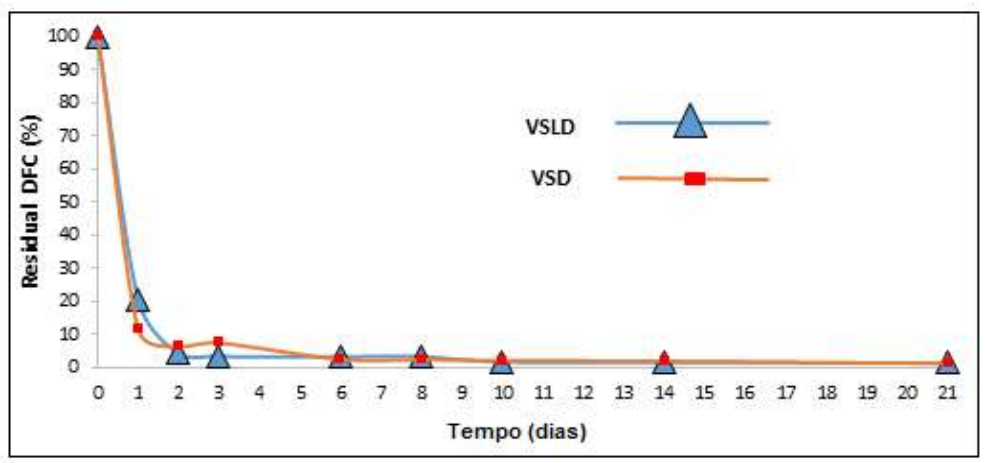

Figura 6: Gráfico comparativo entre a porcentagem residual de DFC no substrato com solo e LET fortificado com pesticida (VSLD) e substrato com solo fortificado com pesticida (VSD).

\section{CONCLUSÕES}

O método de extração, clean up e determinação por CGEM otimizado neste estudo, reuniu extração com DCM sob US e clean up com a técnica de extração dispersiva utilizando alumina como fase sólida. 0 método cromatográfico foi definido em modo SIM (m/z 265 e 323) e injeção splitless. A metodologia como um todo apresentou precisão e recuperação aceitáveis, LD e LQ compatíveis com outras metodologias para quantificação de DFC e adequados para acompanhamento do estudo de degradação do analito.

O estudo de degradação do DFC concluiu que houve variação significativa $(p \leq 0,5)$ entre o substrato com solo e o substrato contendo solo e LET durante os três primeiros dias. Embora no primeiro dia o substrato contendo apenas solo apresentou queda maior da concentração do pesticida, nos dois dias seguintes o comportamento se inverteu evidenciando favorecimento do LET na queda de concentração do pesticida no substrato. A partir do sexto dia a concentração de DFC se estabilizou em ambos vasos, evidenciando maior variância na concentração no substrato com apenas solo até o vigésimo primeiro dia.

\section{REFERÊNCIAS}

ANVISA. Agência Nacional de Vigilância Sanitária. Resolução RE n. 4.976 de 30/12/14. Brasília: DOU, 2015.

ARYA, R.; SHARMA, A. K.. Bioremediation of carbendazim, a benzimidazole fungicide using Brevibacillus borstelensis and Streptomyces albogriseolus together. Current

Pharmaceutical Biotechnology, v.17, n.2, p.185-189, 2015. DOI: http://doi.org/10.2174/1389201016666150930115737

AZEVEDO, M. M.; FARIA-RAMOS, I.; CRUZ, L. C.; PINA-VAZ, C.; GONCALVES RODRIGUES, A.. Genesis of azole antifungal resistance from agriculture to clinical settings. Journal of agricultural and food chemistry, v.63, n.34, p.7463-7468, 2015. DOI: https://doi.org/10.1021/acs.jafc.5b02728

BANERJEE, K.; OULKAR, D. P; PATIL, S. H.; DASGRUPTA S.;
ADSULE, P. G.. Degradation kinetics and safety evaluation of tetraconazole and difenoconazole residues in grape. Pest Management Science: formerly Pesticide Science, v.64, n.3, p.283-289, 2008. DOI: https://doi.org/10.1002/ps.1524

BOHM, G.; KARSBURG, R.; HEIDRICH, C.; BOHM, E.; MACHADO, R.. Effects of diferent sewage sludge concentrations on soil and cultivated Raphanussativus $L$. American Journal of Experimental Agriculture, v.10, n.3, p.1-7, 2016.

BÜNEMANN, E. K.; BONGIORNO, J.; BAI, Z.; CREAMER, R. E.; DE DEYN, G.; DE GOEDE, R.; FLESKENS, L.; GEISSEN, V.; KUYPER, T. W.; MÄDER, P. PULLEMAN, M.; SUKKEL, W.; VAN GROENIGEN J. W.; BRUSSAARD, L.. Soil quality - A critical review. Soil Biology and Biochemistry, v.120, p.105-125, 
2018. DOI: https://doi.org/10.1016/j.soilbio.2018.01.030

CHANG, L.; CHANG, C. M.. A QSAR Study on the Persistence ofFungicides in the Environment. International Journal of Quantitative Structure-Property Relationships, v.4, p.100116, 2019. DOI: http://doi.org/10.4018/IJQSPR.2019040105

CHENG, J.; LEE, X.; GAO, W.; CHEN, YI.; PAN, W.; TANG, Y.. Effect of biochar on the bioavailability of difenoconazole and microbial community composition in a pesticidecontaminated soil. Appliedsoilecology, v.121, p.185-192, 2017. DOI: https://doi.org/10.1016/i.apsoil.2017.10.009

EVANS, T.. A Review of Current Knowledge. Sewage Sludge: Operational and Environmental Issues. 3 ed.

Buckinghamshire: Foundation for Water Research, 2011.

FILIMON, M. N.; POPESCU, R.; VERDES, D.; DUMITRESCU, G.; VOIA, O. S.; AHMADI, M.; DRONCA, D.. The Effects of Difenoconazole Treatment on Microorganism from Soil. Communities, v.14, n.17, p.20, 2018.

FISHER, M. C.; HAWKINS, N. J.; SANGLARD, D.; GURR, S. J.. Worldwide emergence of resistance to antifungal drugs challenges human health and food security. Science, v.360, n.6390, p.739-742, 2018. DOI:

http://doi.org/10.1126/science.aap7999

GARCIA-RUBIO, R.; CUENCA-ESTRELLA, M.; MELLADO, E.. Triazole resistance in Aspergillus species: an emerging problem. Drugs, v.77, n.6, p.599-613, 2017. DOI: https://doi.org/10.1007/s40265-017-0714-4

GARCÍA-VALCÁRCEL, A. I.; TADEO, J. L.. Determination of azoles in sewage sludge from Spanish wastewater treatment plants by liquid chromatography-tandem mass spectrometry. Journal of separation science, v.34, n.11, p.1228-1235, 2011. DOI:

https://doi.org/10.1002/jssc.201000814

GONÇALVES C.; ALPENDURADA M. F.. Assessment of pesticide contamination in soil samples from an intensive horticulture area, using ultrasonic extraction and gas chromatography-mass spectrometry. Talanta, v.65, p.11791189, 2005. DOI:

https://doi.org/10.1016/j.talanta.2004.08.057

GUPTA, S.; WALI, A.; GUPTA, M.; ANNEPU S. K.. Fungi: An Effective Tool for Bioremediation. In: Plant-Microbe Interactions in Agro-Ecological Perspectives. Springer, 2017. p.593-606.

HENDRIKS, C. M. J.; STOORVOGEL, J. J.; LUTZ, F.; CLAESSENS, L.. When can legacy soil data be used, and when should new data be collected instead?. Geoderma, v.348, p.181-188, 2019. DOI: https://doi.org/10.1016/j.geoderma.2019.04.026

HLADIK, M. L.; MCWAYNE, M. M.. Methods of Analysis: Determination of Pesticides in Sediment Using Gas Chromatography/Mass Spectrometry. Techniques and Methods 5-C3. Reston: USGS, 2012.

INGELMO, F.; MOLINA, M. J.; SORIANO, M. D.; GALLARDO, A.; LAPEÑA, L.. Influence of organic matter transformations on the bioavailability of heavy metals in a sludge based compost. Journal of Environmental management, v.95, p.s104-109, 2012. DOI:

https://doi.org/10.1016/j.jenvman.2011.04.015

JAISWAL, S.; SINGH, D. K.; SHUKLA, P.. Gene editing and systems biology tools for pesticide bioremediation: A review. Frontiers in Microbiology, v.10, 2019. DOI: https://doi.org/10.3389/fmicb.2019.00087

KACPRZAK, M.; NECZAJ, E.; FIJALKOWSKI, K.; GROBELAK, A.; GROSSER, A.; WORWAG, M.; RORAT, A.; BRATTEBO, H. ALMAS, A.; SINGH, B. R.. Sewage sludge disposal strategies for sustainable development. Environmental research, v.156, p.39-46, 2017. DOI: https://doi.org/10.1016/i.envres.2017.03.010

KANG, D.; ZHANG, H.; CHEN Y.; WANG, F.; SHI, L.; HU, D.; ZHANG, K.. Simultaneous determination of difenoconazole, trifloxystrobin and its metabolite trifloxystrobin acid residues in watermelon under field conditions by GCMS/MS. Biomedical Chromatography, v.31, n.11, 2017. DOI: https://doi.org/10.1002/bmc.3987

LANÇAS, F. M.. Validação de métodos cromatográficos para análise. São Carlos: RiMa, 2004.

LI, J.; DONG, F.; CHENG, Y.; LIU, X.; XU, J. LI, Y.; CHEN, X.; KONG, Z.; ZHENG, Y.. Simultaneous enantioselective determination of triazole fungicide difenoconazole and its main chiral metabolite in vegetables and soil by normalphase high-performance liquid chromatography. Analytical and bioanalytical chemistry, v.404, n.6-7, p.2017-2031, 2012. DOI: https://doi.org/10.1007/s00216-012-6240-z

MAQBOOL, Z.; HUSSAIN, S.; IMRAN, M.; MAHMOOD, F.; SHAHZAD, T.; AHMED, Z.. Perspectives of using fungi as bioresource for bioremediation of pesticides in the environment: a critical review. Environmental Science and Pollution Research, v.23, n.17, p.16904-16925, 2016. DOI: https://doi.org/10.1007/s11356-016-7003-8

MEIS, J. F.; CHOWDHARY, A.; RHODES, J. L.; FISHER, M. C.; VERWEIJ, P. E.. Clinical implications of globally emerging azole resistance in Aspergillus fumigatus. Phil. Trans. R. Soc. B, v.371, 2016. DOI: http://dx.doi.org/10.1098/rstb.2015.0460

MÓNICA, P.; DARWIN, R. O.; MANJUNATHA, B.; ZUÑIGA, J. J.; DIEGO, R.; BRYAN, R. B.; MULLA, S. I.; MADELLA, N. R.. Evaluation of various pesticides-degrading pure bacterial cultures isolated from pesticide-contaminated soils in Ecuador. African Journal of Biotechnology, v.15, n.40, p.2224-2233, 2016. DOI: http://dx.doi.org/10.5897/AJB2016.15418

MOREIRA; A.; MALAVOLTA, E.. Dinâmica da matéria orgânica e da biomassa microbiana em solo submetido a diferentes sistemas de manejo na Amazônia ocidental. Pesquisa Agropecuária Brasileira, v.39, n.11, p.1003-1110, 2004.

PRASAD, R.; SHAH, A. H.; RAWAL, M. K.. Antifungals: Mechanism of Action and Drug Resistance. In: Yeast Membrane Transport. Springer, 2016. p.327-349. DOI: http://doi.org.10.1007/978-3-319-25304-6 14

REY, F.; BIFULCO, C.; BISCHETTI, G. B.; BOURRIER, F.; DE CESARE, G., FLORINETH, F.; GRAF, F.; MARDEN, M.; 
MICKOVSKI, B.; PHILLIPS, C.; PEKLO, K.; POESEN, J.; POLSTER, D.; PRETI, F.; RAUCH, H. P.; RAYMOND, P.; SANGALLI, P.; TARDIO, G.; STOKES, A.. Soil and water bioengineering: Practice and research needs for reconciling natural hazard control and ecological restoration. Science of the Total Environment, v.648, p.1210-1218, 2019. DOI: https://doi.org/10.1016/j.scitotenv.2018.08.217

SANCHES FILHO, P. J.; MESQUITA, G. O.. Determinação de hidrocarbonetos em sedimentos de canais de drenagem pluvial Pelotas/RS. Revista Ibero Americana de Ciências Ambientais, v.9, n.3, p.38-49, 2018. DOI: http://doi.org/10.6008/CBPC2179-6858.2018.003.0004

SHAHINASI, E.; BRAHUSHI, F.; DEVOLLI, A.; KODRA, M.. The ecotoxicology of pesticides group of triazole and their use to control apple scab (Venturiaina equalis). Journal of Hygienic Engineering and Design, v.18, p.36-42, 2017.

SHALABY, A. R.; EMAM, W. H.; ANWAR, M. M.. Mini-column assay for rapid detection of malachite green in fish.

Foodchemistry, v.226, p.8-13, 2017. DOI:

https://doi.org/10.1016/i.foodchem.2017.01.045

SHI, Y. H.; XIAO, J. J.; FENG, R. P.; LIU, Y. Y.; LIAO, M.; WU, X. W.; HUA, R.; CAO, H.. Factors affecting the bioaccessibility and intestinal transport of difenoconazole, hexaconazole, and spirodiclofen in human caco- 2 cells following in vitro digestion. Journal of agricultural and food chemistry, v.65, n.41, p.9139-9146, 2017.

SPINA, F.; CECCHI, G.; LANDINEZ-TORRES, A.; PECORARO, L.; RUSSO, F.; WU, B.; CAI, L.; LIU, X. Z.; TOSI, S.; VARESE, G. C.; ZOTTI, M.; PERSIANI, A. M.. Fungi as a toolbox for sustainable bioremediation of pesticides in soil and water. Plant Biosystems - An International Journal Dealing with all Aspects of Plant Biology, v.152, n.3, p.474-488, 2018. DOI: https://doi.org/10.1080/11263504.2018.1445130

STORCK, V.; NIKOLAKI, S.; PERRUCHON, C.; PERTILE, G.; BAGUELIN, C.; KARAS, P.; SPOR, A.; DEVERS, M.; PAPADOPOULOU, E.; SIBOURG, O.; MALANDAIN, C.. Lab to field assessment of the ecotoxicological impact of chlorpyrifos, isoproturon or tebuconazole on the diversity and composition of the soil bacterial community. Frontiers in microbiology, v.9, p.1412, 2018. DOI:

https://doi.org/10.3389/fmicb.2018.01412

SZPYRKA, E.; WALORCZYC, S.. Dissipation of difenoconazole in apples used for production of baby food. Journal of environmental science and health, part b, v.52, n.2, p.1-7,
2016. DOI:

https://doi.org/10.1080/03601234.2016.1248141

TEDESCO, M. J.; BISSANI, C. A.; BOHNEN, H.; VOLKWEISS, S. J. Análises de solo, plantas e ouros materiais. Porto Alegre: Universidade Federal do Rio Grande do Sul, 1995.

TWOHIG, M.; AUBIN, A.; O'LEARY, M.; DEPHILLIPO, M.; PERINE, S. C.; STUBBS, D. R.. Enantiomeric and Diastereomeric Resolutions of Chiral Pesticides by ACQUITY UPC $^{2}$ with UV Detection. Milford: Waters Corporation, 2013

EPA. Environmental Protection Agency. US EPA method 3550C. US Government Printing Office. Washington: EPA, 2000.

VAN DEN DOOL, H.; KRATZ, P. D.. A generalization of the retention index system including linear temperature programmed gas-liquid partition chromatography. Journal of Chromatography A, v.11, p.463-471, 1963. DOI: https://doi.org/10.1016/S0021-9673(01)80947-X

VON MÜHLEN, C.. Índices de retenção em cromatografia gasosa bidimensional abrangente. Sci Chromatogr, v.1, n.3, p.21-8, 2009.

ZHANG, Q.; ZHOU, L.; YANG, Y.; HUA, X.; SHI, H.; WANG, M. Study on the stereoselective degradation of three triazole fungicides in sediment. Ecotoxicology and environmental safety, v.117, p.1-6, 2015a. DOI:

https://doi.org/10.1016/j.ecoenv.2015.03.014

ZHANG, Z.; JIANG, W.; JIAN, Q.; SONG, W.; ZHENG, Z., WANG, D.; LIU, X.. Residues and dissipation kinetics of triazole fungicides difenoconazole and propiconazole in wheat and soil in Chinese fields. Food chemistry, v.168, p.396-403, 2015b. DOI:

https://doi.org/10.1016/i.foodchem.2014.07.087

ZHAO, F.; LIU, J.; HAN, B.; LUO, J.. Investigation and Validation of Detection of Storage Stability of Difenoconazole Residue in Mango. Journal of Food Quality, v.2019, p.1-8, 2019. DOI: https://doi.org/10.1155/2019/5641643

ZHEN, M.; SONG, B.; LIU, X.; CHANDANKERE, R.; TANG, J.. Biochar-mediated regulation of greenhouse gas emission and toxicity reduction in bioremediation of organophosphorus pesticide-contaminated soils. Chinese journal of chemical engineering, v.26, n.12, p.2592-2600, 2018. DOI: https://doi.org/10.1016/i.cjche.2018.01.028

A CBPC - Companhia Brasileira de Produção Científica (CNPJ: 11.221.422/0001-03) detém os direitos materiais desta publicação. Os direitos referem-se à publicação do trabalho em qualquer parte do mundo, incluindo os direitos às renovações, expansões e disseminações da contribuição, bem como outros direitos subsidiários. Todos os trabalhos publicados eletronicamente poderão posteriormente ser publicados em coletâneas impressas sob coordenação da Sustenere Publishing, da Companhia Brasileira de Produção Científica e seus parceiros autorizados. Os (as) autores (as) preservam os direitos autorais, mas não têm permissão para a publicação da contribuição em outro meio, impresso ou digital, em português ou em tradução. 